\title{
Experience Salience Gates Endocannabinoid Signaling at Hypothalamic Synapses
}

\author{
Jaclyn I. Wamsteeker Cusulin, ${ }^{1,2}$ Laura Senst, ${ }^{1,2}$ G. Campbell Teskey, ${ }^{1,3,4}$ and Jaideep S. Bains ${ }^{1,2}$ \\ ${ }^{1}$ Hotchkiss Brain Institute, ${ }^{2}$ Department of Physiology and Pharmacology, ${ }^{3}$ Department of Psychology, and ${ }^{4}$ Department of Cell Biology and Anatomy, \\ University of Calgary, Calgary, Alberta, T2N 4N1, Canada
}

\begin{abstract}
Alterations in synaptic endocannabinoid signaling are a widespread neurobiological consequence of many in vivo experiences, including stress. Here, we report that stressor salience is critical for bidirectionally modifying presynaptic CB-1 receptor (CB1R) function at hypothalamic GABA synapses controlling the neuroendocrine stress axis in male rats. While repetitive, predictable stressor exposure impairs presynaptic CB1R function, these changes are rapidly reversed upon exposure to a high salience experience such as novel stress or by manipulations that enhance neural activity levels in vivo or in vitro. Together these data demonstrate that experience salience, through alterations in afferent synaptic activity, induces rapid changes in endocannabinoid signaling.
\end{abstract}

Key words: endocannabinoids; GABA; glucocorticoids; novelty; stress; synapse

\section{Introduction}

Endocannabinoids (eCBs) are nearly ubiquitous retrograde messengers at synapses throughout the nervous system (Regehr et al., 2009; Castillo et al., 2012). eCB signaling, and particularly presynaptic $\mathrm{CB} 1$ receptor (CB1R) function is labile, exhibiting bidirectional plasticity following many in vivo experiences such as stress (Castillo et al., 2012; Iremonger et al., 2013). What specifically about these experiences drives changes in synaptic eCB signaling, however, remains unclear. One possibility is that the activity levels of the presynaptic axons and terminals that express CB1Rs is deterministic for eCB signaling efficacy (Chen et al., 2003, 2007; Földy et al., 2006; Zhu and Lovinger, 2007; Heifets et al., 2008; Lourenço et al., 2010). Since activity in neural circuits is driven by experience, we asked whether presynaptic CB1R function reflects the representation of an experience in discrete neural circuits.

To test this idea, we examined GABA synapses onto parvocellular neuroendocrine cells (PNCs) in the paraventricular nucleus (PVN) of the hypothalamus. These cells serve as a critical node for the integration of stress circuit activity by coordinating the output of the hypothalamic-pituitary-adrenal (HPA) axis. Such "stress circuitry" is finely tuned to distinguish valence of experience-both in terms of negative or positive affective quality, but

Received Jan. 14, 2014; revised Feb. 26, 2014; accepted March 19, 2014.

Author contributions: J.I.W.C., G.C.T., and J.S.B. designed research; J.I.W.C. and L.S. performed research; G.C.T. contributed unpublished reagents/analytic tools; J.I.W.C. analyzed data; J.I.W.C. and J.S.B. wrote the paper.

This work was supported by an operating grant from the Canadian Institutes for Health Research. Scholarship support was provided by Alberta Innovates-Health Solutions (J.I.W.C.), the Hotchkiss Brain Institute (J.I.W.C., L.S.), and the Canadian Consortium for the Investigation of Cannabinoids (J.I.W.C.). We thank all Bains lab members for thoughtful discussion; Drs. Matthew Hill, Wataru Inoue, and Tamás Füzesi for critical evaluations of earlier drafts of this manuscript; and Cheryl Sank for technical assistance.

The authors declare no competing financial interests.

Correspondence should be addressed to Jaideep S. Bains, Hotchkiss Brain Institute, University of Calgary, 3330 Hospital Drive, NW. Calgary, Alberta T2N 4N1, Canada. E-mail: jsbains@ucalgary.ca.

DOI:10.1523/JNEUROSCI.0163-14.2014

Copyright $\odot 2014$ the authors $\quad 0270-6474 / 14 / 346177-05 \$ 15.00 / 0$ also between novelty and predictability of stressful experiences (Pecoraro et al., 2006; McEwen, 2007). eCBs are dynamic regulators of stress adaptation (Hill et al., 2010). Reinforcement of predictability by repeated exposure to a homotypic stressor results in a downregulation of presynaptic CB1Rs and a loss of retrograde eCB signaling at PNC synapses (Wamsteeker et al., 2010). Here we hypothesized that changes to CB1R function may correlate with the salience of an experience, which is encoded by the relative activity of a specific neural network. We report that exposing male rats (P21-P35) to a single, novel stress, following repeated homotypic stress, resulted in rapid recovery of eCB signaling. This recovery was mimicked by the general recruitment of limbic circuits by electroconvulsive seizure (ECS) in vivo, or by manipulations that increase neural activity in vitro. Together our findings suggest that while repeated external stressors decrease eCB signaling, robust and sustained network-dependent activity driven by higher salience experiences rapidly reverses such changes.

\section{Materials and Methods}

Animal handling and stress procedures. All protocols were performed in accordance with guidelines of the Canadian Council for Animal Care, with approval from the University of Calgary Animal Care Committee. Male Sprague Dawley rats (P21-P35; Charles River) housed with one to three littermates had ad libitum access to food and water and were maintained on a $12 \mathrm{~h}$ light/dark schedule. Stressor exposure (immobilization, forced swim, or predator odor) took place 2-3 h after the onset of light. Immobilization (immo.) consisted of $30 \mathrm{~min}$ cervical and caudal restriction within a Plexiglas cylinder. Forced swim consisted of 20 min swimming in an opaque plastic bucket $(40 \mathrm{~cm}$ internal diameter) filled with $30-32^{\circ} \mathrm{C}$ water. Exposure to predator odor $(30 \mathrm{~min})$ occurred in an empty cage in which a 2,5-dihydro-2,4,5-trimethylthiazoline (Contech)soaked tissue was placed on a wire rack above. Repeated stress took place in the same location and time each day before return to home cage and environment. Unless the last stressor was followed by ECS, animals were immediately anesthetized for slice preparation. For ECS delivery, both sham and ECS-treated animals were fitted with saline-soaked ear clips. 
For ECS, a GSC700 shock generator (Grason-Stadler) was used to deliver $40 \mathrm{~mA}$ current across the skull in a $0.2 \mathrm{~s}$ train with $60 \mathrm{~Hz}$ biphasic sinewave pulses. This was sufficient to generate sustained facial and forelimb clonic motor movements. After ECS/sham, rats were placed in a clean cage for $10 \mathrm{~min}$.

Electrophysiology. After anesthesia (isoflurane inhalation), brains were removed and chilled in slicing solution $\left(0-4^{\circ} \mathrm{C}, 95 \% \mathrm{O}_{2}\right)$ containing the following (in mM): $87 \mathrm{NaCl}, 2.5 \mathrm{KCl}, 0.5 \mathrm{CaCl}_{2}, 7 \mathrm{MgCl}_{2}, 25 \mathrm{NaHCO}_{3}, 25$ D-glucose, $1.25 \mathrm{NaH}_{2} \mathrm{PO}_{4}$, and 75 sucrose. Coronal hypothalamic sections $(300 \mu \mathrm{m})$ were prepared on a vibrating slicer (Leica) and allowed to recover in artificial CSF (ACSF; at $30^{\circ} \mathrm{C}$ ), which contained the following (in mM): $126 \mathrm{NaCl}, 2.5 \mathrm{KCl}, 26 \mathrm{NaHCO}_{3}, 2.5 \mathrm{CaCl}_{2}, 1.5 \mathrm{MgCl}_{2}, 1.25$ $\mathrm{NaH}_{2} \mathrm{PO}_{4}$, and 10 glucose. All recordings were made in ACSF $\left(30-32^{\circ} \mathrm{C}\right.$, $\left.95 \% \mathrm{O}_{2}\right)$ containing 6,7-dinitroquinoxaline-2,3-dione (10 $\mu \mathrm{M}$; Tocris Bioscience) to block AMPAR/kainate transmission. Whole-cell recordings were made with borosilicate electrodes (3-6 $\mathrm{M} \Omega$ resistance) filled with a recording solution containing the following (in $\mathrm{mM}$ ): 108 K-gluconate, $2 \mathrm{MgCl}_{2}, 8 \mathrm{Na}$-gluconate, $8 \mathrm{KCl}, 1 \mathrm{~K}_{2}$-EGTA, $4 \mathrm{~K}_{2}$-ATP, 0.3 $\mathrm{Na}_{3}$-GTP, and $10 \mathrm{~mm}$ HEPES. Signals were amplified, low-pass filtered at $1 \mathrm{kHz}$, digitized at $10 \mathrm{kHz}$ (Multiclamp 700B and Digidata 1322; Molecular Devices) and recorded for off-line analysis (pClamp 9.2; Molecular Devices). PNCs were identified (1) anatomically using an upright microscope (Zeiss Axioskop 2 FS Plus) fitted with differential interference contrast optic and (2) electrophysiologically using defined criteria (Luther et al., 2002; Wamsteeker Cusulin et al., 2013).

Cells were voltage clamped at $-80 \mathrm{mV}$ and a monopolar electrode (positioned 25-50 $\mu \mathrm{m}$ medial to the cell body) was used to deliver pairs of stimuli ( $50 \mathrm{~ms}$ interval repeated at $0.2 \mathrm{~Hz}$ ) to evoke IPSCs. Data were evaluated as a percentage change in evoked IPSC (eIPSC) amplitude (peak inward current relative to mean holding current $50 \mathrm{~ms}$ before both stimuli) following depolarization (10 s bins) or drug (1 min bins). Paired-pulse ratio (PPR; eIPSC2/eIPSC1) was calculated using mean eIPSC amplitudes from 2 min bins. The depolarization-induced suppression of inhibition (DSI) paradigm consisted of the following: $1 \mathrm{~min}$ baseline, $5 \mathrm{~s}$ postsynaptic depolarization (to $+20 \mathrm{mV}$ for $5 \mathrm{~s}$ ) and $>2 \mathrm{~min}$ postrecording. DSI magnitude was considered to be the maximal percentage change in eIPSC amplitude, which occurred at $0-10 \mathrm{~s}$ following depolarization. For assessment of CB1R function, WIN 55,212-2 (5 $\mu \mathrm{M}$; Sigma) was applied via perfusion pump after $10 \mathrm{~min}$ of baseline recording, followed by AM251 (10 $\mu \mathrm{M}$; Tocris Bioscience) 20 min later. Spontaneous IPSCs (sIPSCs) were detected using Mini Analysis (Synaptosoft). Only recordings with stable access resistance $(<20 \mathrm{M} \Omega$ and $<15 \%$ change) were accepted for analysis.

Statistical analysis. Grouped data consist of neuron recordings $(n)$ from a minimum of $N=3$ rats from two or more different litters. Differences in DSI magnitude or basal PPR between experimental groups were assessed by one-way ANOVA with Newman-Keuls post-test (GraphPad Prism). CB1R agonist/antagonist effects on eIPSC amplitude/PPR were assessed by two-way ANOVA with Fisher's LSD post-test. In some cases (where stated), one-sample tests or Student's $t$ tests were used; $p<0.05$ was considered level of statistical significance.

\section{Results}

We obtained whole-cell voltage-clamp recordings from PNCs in PVN slices from male rats that were either naive or exposed to a repeated stress regimen (Fig. $1 A, B$ ). In the naive group, depolarization of PNCs (to $+20 \mathrm{mV}$ for $5 \mathrm{~s}$ ) induced a short-term suppression of evoked $\mathrm{GABA}_{\mathrm{A}}$ receptor-mediated eIPSCs (45.2 \pm $4.9 \%$ suppression of eIPSC amplitude at $0-10 \mathrm{~s}$ postdepolarization; Fig. 1C,F). This DSI is CB1R mediated (Wamsteeker et al., 2010) and was unaffected by a single episode of immo. (DSI: $40.8 \pm 4.2 \%$; Fig. $1 F$ ), but was attenuated by repetitive exposure to homotypic stress ( $5 \mathrm{~d}$ immo. DSI: $10.6 \pm 2.5 \%$ ).

Increases in afferent activity amplify CB1R-mediated synaptic signaling (Chen et al., 2007; Zhu and Lovinger, 2007; Lourenço et al., 2010). Since enhanced activity in afferents to PVN has been reported following exposure to a novel stressor (Bhatnagar and
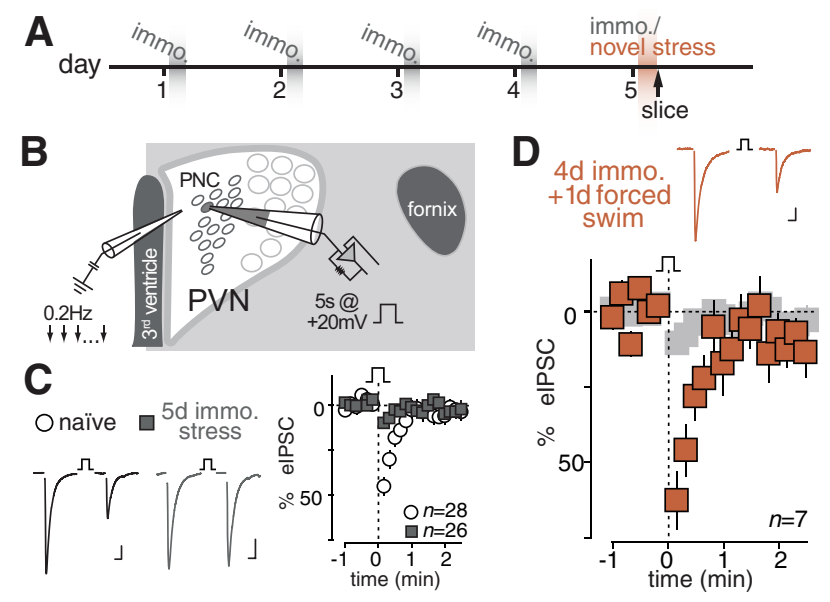

E
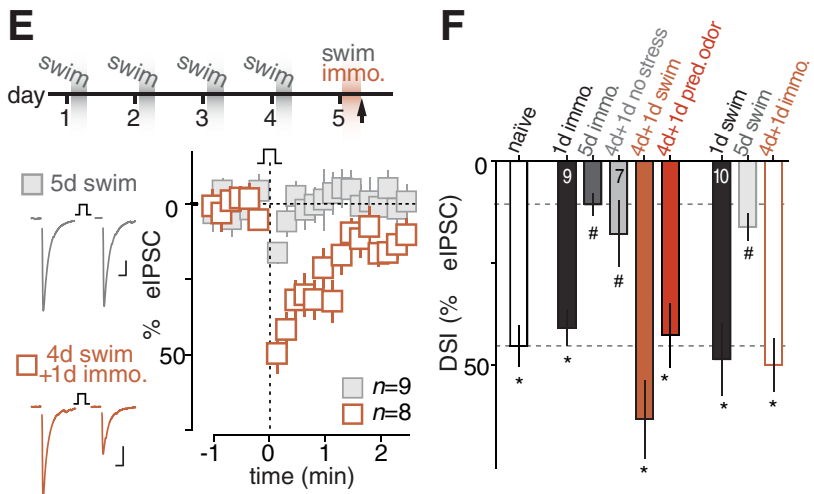

Figure 1. Restoration of eCB signaling by novel stress. Overview of the stressor paradigm $(A)$ and the DSI paradigm $(\boldsymbol{B})$ used to assess retrograde eCB signaling at GABA synapses onto PNCS in the hypothalamic PVN. C, Left, Sample voltage-clamp elPSC trace from a naive rat (black) and a rat subjected to 30 min of immobilization stress (immo.) repeated daily for $5 \mathrm{~d}(5 \mathrm{~d})$. Traces taken from baseline (left) and immediately after postsynaptic depolarization $(0-0.25 \mathrm{~min}$ right). Right, Summary of DSI, plotted as percentage suppression of elPSC amplitude for each group. D, Sample elPSC traces (above) and summary (below) showing recovery of DSI when $4 \mathrm{~d}$ immo. is followed by $1 \mathrm{~d}$ of forced swim for $15 \mathrm{~min}$. $\boldsymbol{E}$, Sample traces (left) and DSI summary (right) for groups exposed to $5 \mathrm{~d}$ forced swim stress or $4 \mathrm{~d}$ swim stress and $1 \mathrm{~d}$ immo. shows similar stress-induced loss and novelty-associated reversal of DSI. $F$, Summary of DSI magnitude across conditions. Naive and $5 \mathrm{~d}$ immo. means indicated by dashed lines. Overall ANOVA: $F_{(8,103)}=10.0 ; p<0.0001$. Post hoc analysis values: ${ }^{\#} p<0.05$ versus naive, ${ }^{*} p<0.05$ versus $5 \mathrm{~d}$ immo.; $n$ for groups not already shown inset within bars. Scale bars: $50 \mathrm{pA} / 10 \mathrm{~ms}$. Data expressed as mean \pm SEM.

Dallman, 1998), we hypothesized that a novel (or heterotypic) stressor may be an appropriate physiological stimulus to effectively re-engage diminished eCB signaling. To test this, we subjected rats to $4 \mathrm{~d}$ of repeated immo. ( $4 \mathrm{~d}$ immo.) followed, on the fifth day, by either no stressor or one of two novel stressors. DSI was unchanged in the group not subjected to stress on day 5 $(17.8 \pm 7.9 \%$; Fig. $1 F)$, confirming an absence of passive recovery of CB1Rs within this time frame. In contrast, the group challenged on day 5 with a mixed physical/psychogenic stressor (forced swim, $20 \mathrm{~min}, 30-32^{\circ} \mathrm{C}$ ) showed an immediate recovery of DSI ( $63.1 \pm 9.3 \%$; Fig. $1 D, F)$. DSI also recovered following 30 min exposure to a predator odor $(42.6 \pm 7.6 \%$; Fig. $1 F)$. Next we asked whether this recovery of eCB signaling could be attributed to either the modality of stressors used or the order in which the stressors were presented. First, we confirmed that a single episode of forced swim alone did not alter DSI (swim: $48.5 \pm 8.7 \%$; Fig. $1 F)$. Second, subjecting animals to repeated swim stress resulted in loss of DSI ( $5 \mathrm{~d}$ swim: $16.0 \pm 3.2 \%$; Fig. $1 E, F$ ). Finally when 
immo. was presented as the novel stress after repeated swim stress, this reversed the loss of DSI ( $4 \mathrm{~d}$ swim $+1 \mathrm{~d}$ immo.: $49.8 \pm$ $6.3 \%$; Fig. $1 E, F)$. These data indicate that a single exposure to a novel stressor is sufficient to immediately reverse the loss of eCB signaling induced by repetitive homotypic stress.

Next, we hypothesized that if novel stress-induced enhancement of eCB signaling is indeed a consequence of increased activity in PVN afferents, then experimental manipulations that increase afferent activity should have similar effects. First, we tested in vivo ECS, which causes a robust increase in limbic afferent-, PNC, and HPA-axis activation (Allen et al., 1974; Herman et al., 1989; Young et al., 1990; Jansson et al., 2006). We delivered either ECS or a sham ECS (SHAM: no electrical current) to rats that had been exposed to $5 \mathrm{~d}$ immo. (Fig. $2 A$ ); a naive group also received ECS. Slices were prepared $10 \mathrm{~min}$ after each treatment. In the naive group, DSI was unaffected by ECS ( $48.5 \pm$ $7.0 \%$; Fig. $2 B, E)$. In the $5 \mathrm{~d}$ immo. group, DSI recovered following ECS $(62.0 \pm 4.9 \%$; Fig. $2 C, E)$. This could not be attributed to the handling procedure, as DSI remained unchanged in SHAM animals (18.3 $\pm 8.0 \%$; Fig. $2 D, E$ ). Loss of DSI in PNCs following repetitive stress is attributable to reduced function of presynaptic CB1Rs, evidenced by a lower maximal synaptic response to CBR agonists (Wamsteeker et al., 2010). To determine whether the observed recovery of DSI is a consequence of recovery of CB1R function, we assayed sensitivity of eIPSCs to a near-saturating concentration of the CB1R ligand, WIN55,212-2 (WIN; $5 \mu \mathrm{M}$ ). WIN was more effective in the ECS-treated group (to $72.4 \pm$ $9.1 \%$ reduction; Fig. $2 \mathrm{~F}-\mathrm{H}$ ) than in the $5 \mathrm{~d}$ immo. group that received only sham ECS treatment (eIPSC: $22.2 \pm 11.2 \%$ reduction, PPR: $106.4 \pm 6.2 \%$ baseline; Fig. $2 F-H$ ). In the ECS group, WIN-induced inhibition was also accompanied by a robust increase in PPR, consistent with a presynaptic locus of WIN action $(53.6 \pm 19.5 \%$ increase; Fig. $2 H)$. The CB1R antagonist AM251 blocked the effects of WIN in both groups (Fig. $2 A-D$ ).

Since CB1R activation reduces synaptic transmission by decreasing release probability ( $\mathrm{Pr})$, one potential explanation for restoration of eCB signaling by ECS/novel stress is that these manipulations affect basal Pr at GABA synapses. We first analyzed the relationship between basal PPR and DSI in naive animals. We observed an inverse relationship between basal PPR and DSI magnitude in this group (Fig. $3 A$ ); i.e., synapses with lower release probability exhibited more robust DSI. Next we examined PPR in each of the treatment groups. We failed to note any significant differences in basal PPR across the different groups (Fig. $3 B$ ) suggesting that changes in basal Pr cannot explain changes in eCB signaling efficacy under the different conditions examined. CB1Rs also show tonic activation (Oliet et al., 2007), raising the possibility that loss and recovery of eCB signaling reflects changes in the proportion of basally activated CB1Rs. Bath application of AM251, however, did not significantly increase eIPSC amplitude in either naive $(18.1 \pm 8.5 \%$ increase; $p=0.07$ one-sample $t$ test $)$ or $5 \mathrm{~d}$ immo. groups ( $7.2 \pm 7.5 \%$ increase; $p=0.37$ one-sample $t$ test) suggesting that tonic CB1R activation is unlikely to explain differences in eCB signaling function (Fig. 3C). Together these data suggest that changes in presynaptic CB1R function at PNC GABA synapses induced by stress are not secondary to changes in basal release probability.

We next asked whether increasing the activity of local afferent inputs to the PVN was sufficient to restore eCB signaling. Modest increases in extracellular potassium $\left[\mathrm{K}^{+}\right]$(to $7.5 \mathrm{~mm}$ ) that globally increase synaptic excitability also enhance CB1R function at hippocampal synapses (Lourenço et al., 2010). We increased $\mathrm{K}^{+}$ from 2.5 to $7.5 \mathrm{~mm}$ in slices from either the naive or $5 \mathrm{~d}$ immo.
A

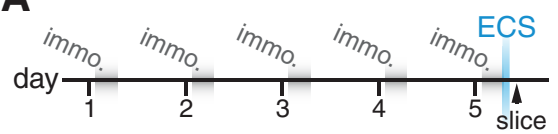

$\mathbf{B}$ naïve $\sqrt{\text { ECS }}$
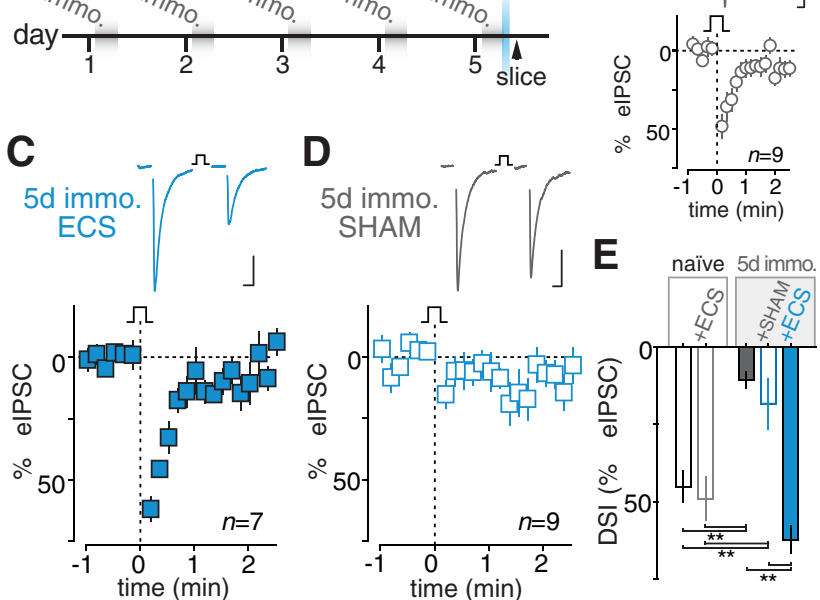

F

G

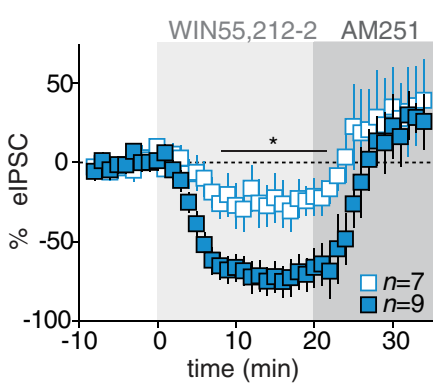

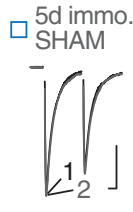

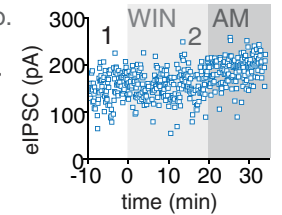

H

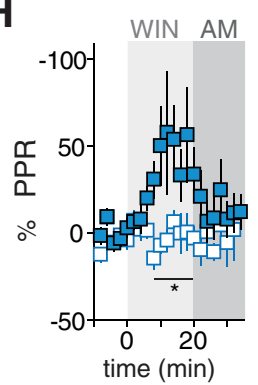

Figure 2. ECS causes experience-specific restoration of retrograde eCB signaling and $C B 1 R$ function. $A$, Five day immo. (or naive) rats were exposed to ECS. $B, D S I$ in naive rats treated with ECS. Sample traces above, summary below. $C, D$, Sample elPSC traces from individual cells (above) and summary graphs (below) of $5 \mathrm{~d}$ immo. animals subjected to ECS or SHAM shows recovery of DSI only with ECS. $E$, Summary of DSI magnitude across conditions. Overall ANOVA: $F_{(4,74)}=16.0 ; p<0.0001$. Post hoc analysis values: ${ }^{* *} p<0.01$. F, Cells from 5 d immo. + ECS (closed squares) or SHAM (open squares) rats were treated with continuous bath application of CB1R agonist WIN55,212-2 (5 $\mu \mathrm{m})$ starting at $0 \mathrm{~min}$, followed by addition of CB1R antagonist/ inverse agonist AM251 (10 $\mu \mathrm{M}$ ) at $20 \mathrm{~min}$. Sample traces of elPSC pairs (50 ms interval) from time points are indicated by numbers on time course graphs plotting elPSC amplitude. Summary graphs of elPSC amplitude $(\boldsymbol{G})$ and PPR $(\boldsymbol{H})$ show differential effects of drugs between conditions. Two-way ANOVAs were performed for elPSC $\left(F_{(1,42)}=79.9, p<0.0001\right)$ and PPR $\left(F_{(1,20)}=34.6, p<0.001\right)$ data. Horizontal line and star indicates post hoc values assessed $p<$ 0.05 . Scale bars: $50 \mathrm{pA} / 10 \mathrm{~ms}$. Data expressed as mean \pm SEM.

group. DSI in the stressed group was now indistinguishable from naive $(58.0 \pm 6.0 \%$; Fig. $4 A, C)$. In naive slices, high $\mathrm{K}^{+}$had no additional effect on DSI $(51.6 \pm 8.4 \%$; Fig. $4 B, C)$. Elevated $\mathrm{K}^{+}$ likely affects excitability nonspecifically at synapses across the cell. Indeed, we found that changes to $\mathrm{eCB}$ signaling were not restricted to the stimulated synapse. In naive and $5 \mathrm{~d}$ immo. cells, the magnitude of DSI at the evoked synaptic inputs exhibited a linear relationship with the magnitude of DSI at spontaneously releasing synapses across the cell (observed as a suppression of sIPSC frequency; Fig. 4D). This trend persisted following high $\mathrm{K}^{+}$treatment (Fig. 4E). 
A

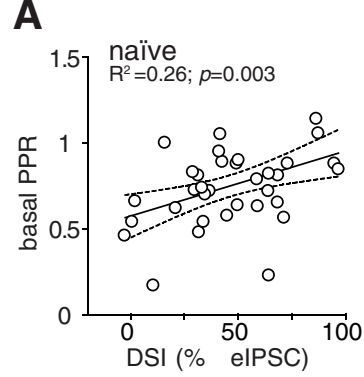

C
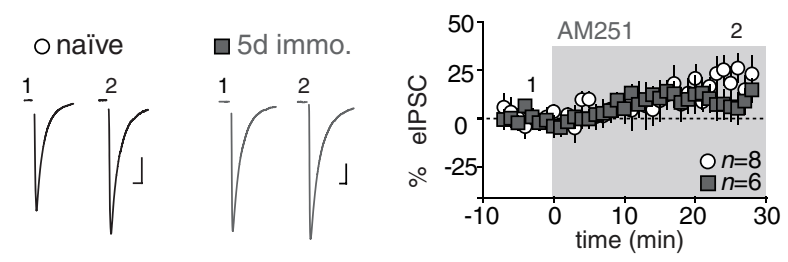

Figure 3. Recovery of eCB signaling is independent from experience-specific modulation of GABA release probability. $\boldsymbol{A}$, Relationship between basal PPR and DSI magnitude in naive cells. Best-fit line plotted with 95\% confidence interval indicates slight tendency for larger DSI at synapses with lower basal release probability. $B$, Bar graph showing no significant changes to basal PPR across various treatment conditions (one-way ANOVA: $F_{(9,149)}=0.89 ; p=0.53$ ). $\boldsymbol{C}$, Sample traces (left) and summary data (right) showing a lack of significant effect of AM251 (10 $\mu \mathrm{M})$ on eIPSC amplitude in either naive or $5 \mathrm{~d}$ immo. cells ( $p>0.05$, two-way ANOVA).

If activity in the afferents determines CB1R function at the synapse, then a focal increase in afferent activity (Chen et al., 2007; Zhu and Lovinger, 2007) should result in synapse-specific recovery of $\mathrm{eCB}$ signaling that is limited largely to the active afferents. To test this, we examined DSI before and after $10 \mathrm{~min}$ of $2 \mathrm{~Hz}$ synaptic stimulation (delivered to the same synapses responsible for the eIPSC). In the $5 \mathrm{~d}$ immo. group, this patterned stimulation enhanced the expression of DSI (before: $13.0 \pm$ 4.9\%, after: $41.0 \pm 3.4 \%$; Fig. $4 F)$, an effect which persisted for at least $25 \mathrm{~min}(27.5 \pm 2.9 \% \mathrm{DSI}$ at $25 \mathrm{~min})$. The repeated afferent recruitment paradigm had no effect on basal eIPSC amplitude $(8.8 \pm 14.7 \%$ change; $p=0.6$ one-sample $t$ test). There was a transient decrease in PPR following patterned stimulation $(14.6 \pm 5.4 \%$ reduction; $p=0.04$ one-sample $t$ test; data not shown), but this did not persist $(2.6 \pm 9.2 \%$ change at $25 \mathrm{~min}$; $p=0.8$ one-sample $t$ test). This paradigm failed to alter DSI in the naive group (before: $44.2 \pm 5.8 \%$, after $41.2 \pm 5.5 \%$; Fig. $4 F$ ). Recovery of DSI by focal afferent activity at the site of evoked GABA release was not accompanied by recovery of CB1R function at synapses that were not subjected to repeated stimulation, i.e., those releasing GABA spontaneously (Fig. 4G) unlike DSI recovery by high $\mathrm{K}^{+}$, ECS (data not shown), or novel stress (Fig. $4 H$ ). More specifically, while the patterned synaptic stimulation recovered both DSI and WIN responsiveness $(47.3 \pm 12.8 \%$ eIPSC reduction, $p=0.01$ one-sample $t$ test; data not shown) of eIPSCs, DSI of spontaneous IPSC frequency remained unaffected (before: $11.4 \pm 6.8 \%$, after: $13.6 \pm 5.6 \%$ ). These data provide support for the idea that restoration of synaptic eCB signaling by a novel stress experience is related to a relatively global afferent activity-induced change in the excitability of local presynaptic contacts.

\section{Discussion}

We show that impairment of retrograde eCB signaling, caused by repeated exposure to the same stressor, is rapidly erased by a novel stressor. This behaviorally induced CB1R recovery is recapitulated by in vivo electroconvulsive seizure or in vitro manipu-
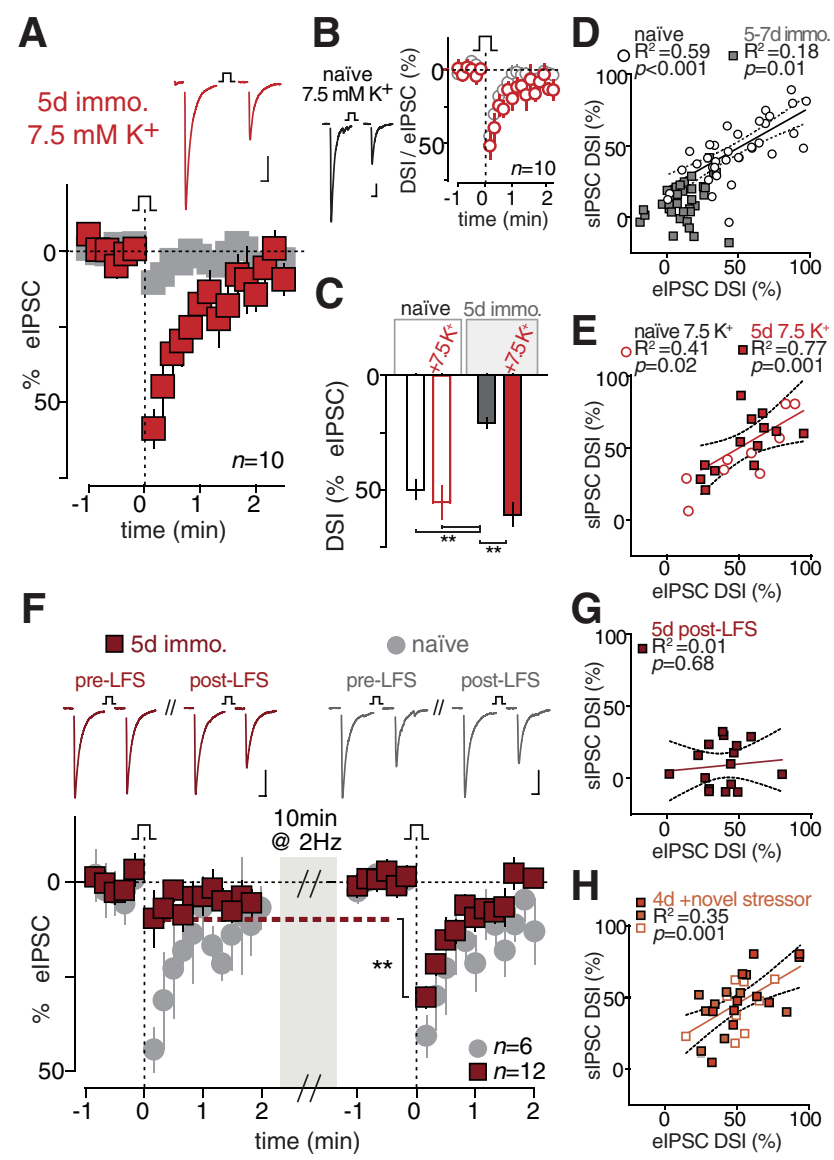

Figure 4. Presynaptic activity state regulates eCB signaling efficacy. A, Top, Sample elPSC traces from individual cells of $5 \mathrm{~d}$ immo. animals recorded in $2.5 \mathrm{~mm}$ (gray) or $7.5 \mathrm{~mm}$ (red) potassium $\left(\mathrm{K}^{+}\right)$ACSF. Bottom, Summary of all cells tested showing recovery of DSI in high $\mathrm{K}^{+}$ ACSF $\left(2.5 \mathrm{~mm} \mathrm{~K}^{+}: n=26 ; 7.5 \mathrm{~mm} \mathrm{~K}^{+}: n=10\right) . \boldsymbol{B}$, Left, Sample elPSC traces from individual cells of naive animals recorded in $2.5 \mathrm{~mm} \mathrm{~K}^{+}$or $7.5 \mathrm{~mm} \mathrm{~K}^{+}$ACSF. Right, Summary of all cells tested $\left(2.5 \mathrm{~mm} \mathrm{~K}^{+}: n=28 ; 7.5 \mathrm{~mm} \mathrm{~K}^{+}: n=10\right)$. C, Summary of DSI magnitude across conditions. Overall ANOVA: $F_{(3,70)}=19.2, p<0.0001$. $\boldsymbol{D}$, Relationship between DSI of elPSC amplitude and spontaneous IPSC (sIPSC) frequency in naive and $5 \mathrm{~d}$ immo. cells. Best-fit line with $95 \%$ confidence interval shown for naive group. $E$, Linear relationship of sIPSC and elPSC DSI after $7.5 \mathrm{~mm} \mathrm{~K}^{+}$in naive and $5 \mathrm{~d}$ stress cells. Five day immo. group best-fit line shown. $\boldsymbol{F}$, Top, Sample elPSC traces from individual cells of $5 \mathrm{~d}$ immo. and naive animals, before and following low-frequency synaptic stimulation (LFS: $2 \mathrm{~Hz}, 10 \mathrm{~min}$ ). Bottom, Summary of DSl in all cells tested showing recovery of DSI following low-frequency stimulation. Peak DSI before and after LFS was significantly different in the $5 \mathrm{~d}$ stress group (unpaired $t$ test: $t, d f(4.7,22) ; p<$ 0.001 ) but unchanged in the naive group $(t, d f(0.4,10) ; p=0.72)$. G, Plot of $s$ IPSC versus elPSC DSI post-LFS in $5 \mathrm{~d}$ immo. cells shows selective recovery of elPSC DSI. $\boldsymbol{H}$, Plot of sIPSC versus elPSC DSI in $4 \mathrm{~d}$ immo. $+1 \mathrm{~d}$ swim (filled dark orange squares), $+1 \mathrm{~d}$ predator odor (filled light orange squares), or $4 \mathrm{~d}$ swim $+1 \mathrm{~d}$ immo. (open squares) shows a recovery of both s/elPSC DSI by novel stressors. Pooled best-fit line shown. Scale bars: $50 \mathrm{pA} / 10 \mathrm{~ms}$. Data expressed as mean \pm SEM. Post hoc analysis values: ${ }^{*} p<0.05,{ }^{* *} p<0.01$.

lations that increase the activity of afferent GABA inputs. These findings suggest that switches in presynaptic eCB signaling capacity reflect experience salience-dependent modulation of circuit activity.

The rapid restoration of CB1R function observed here indicates that loss of CB1R signaling following repeated stress represents a reversible state. DSI loss/recovery occurs regardless of stressor modality, and there is a strong correlation between DSI of evoked and spontaneous IPSCs following ECS, high $\mathrm{K}^{+}$, or novel stress, but not focal synaptic stimulation. This argues that in vivo novel stress restores $\mathrm{eCB}$ signaling through widespread increases in activity across PNC afferents rather than recruiting a 
previously quiescent set of CB1R-expressing inputs. These data are consistent with observations that patterned afferent stimulation, or global elevations in activity during events such as seizure, have enduring effects on DSI (Chen et al., 2007; Zhu and Lovinger, 2007). Interestingly, while presynaptic neuronal firing is required for eCB-LTD at synaptic targets in the hippocampus (Heifets et al., 2008), higher firing rates have been shown to overcome CB1R inhibition entirely (Földy et al., 2006). This suggests that "optimal" CB1R function may be constrained within a set range of presynaptic activity. On the lower limit of this range, presynaptic GPCR function may be strongly impacted by changes to axon terminal second-messenger pathways (Heifets et al., 2008), activity-dependent reinsertion of presynaptic receptors (Pelkey et al., 2005), or changes in cell surface receptor mobility (Mikasova et al., 2008), for example. Together these data support the idea that afferent activity in a given synapse is an important determinant of CB1R function.

The present results demonstrate that an experience with high salience, specifically novel stress, can erase the synaptic effects of repeated stress load, suggesting that shifts in the state of synaptic eCB signaling are controlled by the relative value of an experience. In addition, our data demonstrate that artificial representation of experience, through manipulation of neural and synaptic activity, is sufficient to gate the synaptic availability of the $\mathrm{eCB}$ system. Together these findings suggest that the relative salience an experience may impact information processing in a neural circuit by moving synapses in and out of an optimal working range.

\section{References}

Allen JP, Denney D, Kendall JW, Blachly PH (1974) Corticotropin release during ECT in man. Am J Psychiatry 131:1225-1228. Medline

Bhatnagar S, Dallman M (1998) Neuroanatomical basis for facilitation of hypothalamic-pituitary-adrenal responses to a novel stressor after chronic stress. Neuroscience 84:1025-1039. CrossRef Medline

Castillo PE, Younts TJ, Chávez AE, Hashimotodani Y (2012) Endocannabinoid signaling and synaptic function. Neuron 76:70-81. CrossRef Medline

Chen K, Ratzliff A, Hilgenberg L, Gulyás A, Freund TF, Smith M, Dinh TP, Piomelli D, Mackie K, Soltesz I (2003) Long-term plasticity of endocannabinoid signaling induced by developmental febrile seizures. Neuron 39:599-611. CrossRef Medline

Chen K, Neu A, Howard AL, Földy C, Echegoyen J, Hilgenberg L, Smith M, Mackie K, Soltesz I (2007) Prevention of plasticity of endocannabinoid signaling inhibits persistent limbic hyperexcitability caused by developmental seizures. J Neurosci 27:46-58. CrossRef Medline

Földy C, Neu A, Jones MV, Soltesz I (2006) Presynaptic, activity-dependent modulation of cannabinoid type 1 receptor-mediated inhibition of GABA release. J Neurosci 26:1465-1469. CrossRef Medline

Heifets BD, Chevaleyre V, Castillo PE (2008) Interneuron activity controls endocannabinoid-mediated presynaptic plasticity through calcineurin. Proc Natl Acad Sci U S A 105:10250-10255. CrossRef Medline

Herman JP, Schäfer KH, Sladek CD, Day R, Young EA, Akil H, Watson SJ (1989) Chronic electroconvulsive shock treatment elicits up-regulation of CRF and AVP mRNA in select populations of neuroendocrine neurons. Brain Res 501:235-246. CrossRef Medline

Hill MN, Patel S, Campolongo P, Tasker JG, Wotjak CT, Bains JS (2010) Functional interactions between stress and the endocannabinoid system: from synaptic signaling to behavioral output. J Neurosci 30:1498014986. CrossRef Medline

Iremonger KJ, Wamsteeker Cusulin JI, Bains JS (2013) Changing the tune: plasticity and adaptation of retrograde signals. Trends Neurosci 36:471479. CrossRef Medline

Jansson L, Hellsten J, Tingström A (2006) Region specific hypothalamic neuronal activation and endothelial cell proliferation in response to electroconvulsive seizures. Biol Psychiatry 60:874-881. CrossRef Medline

Lourenço J, Cannich A, Carta M, Coussen F, Mulle C, Marsicano G (2010) Synaptic activation of kainate receptors gates presynaptic $\mathrm{CB}(1)$ signaling at GABAergic synapses. Nat Neurosci 13:197-204. CrossRef Medline

Luther JA, Daftary SS, Boudaba C, Gould GC, Halmos KC, Tasker JG (2002) Neurosecretory and non-neurosecretory parvocellular neurones of the hypothalamic paraventricular nucleus express distinct electrophysiological properties. J Neuroendocrinol 14:929-932. CrossRef Medline

McEwen BS (2007) Physiology and neurobiology of stress and adaptation: central role of the brain. Physiol Rev 87:873-904. CrossRef Medline

Mikasova L, Groc L, Choquet D, Manzoni OJ (2008) Altered surface trafficking of presynaptic cannabinoid type 1 receptor in and out synaptic terminals parallels receptor desensitization. Proc Natl Acad Sci U S A 105:18596-18601. CrossRef Medline

Oliet SH, Baimoukhametova DV, Piet R, Bains JS (2007) Retrograde regulation of GABA transmission by the tonic release of oxytocin and endocannabinoids governs postsynaptic firing. J Neurosci 27:1325-1333. CrossRef Medline

Pecoraro N, Dallman MF, Warne JP, Ginsberg AB, Laugero KD, la Fleur SE, Houshyar H, Gomez F, Bhargava A, Akana SF (2006) From Malthus to motive: how the HPA axis engineers the phenotype, yoking needs to wants. Prog Neurobiol 79:247-340. CrossRef Medline

Pelkey KA, Lavezzari G, Racca C, Roche KW, McBain CJ (2005) mGluR7 is a metaplastic switch controlling bidirectional plasticity of feedforward inhibition. Neuron 46:89-102. CrossRef Medline

Regehr WG, Carey MR, Best AR (2009) Activity-dependent regulation of synapses by retrograde messengers. Neuron 63:154-170. CrossRef Medline

Wamsteeker Cusulin JI, Füzesi T, Inoue W, Bains JS (2013) Glucocorticoid feedback uncovers retrograde opioid signaling at hypothalamic synapses. Nat Neurosci 16:596-604. CrossRef Medline

Wamsteeker JI, Kuzmiski JB, Bains JS (2010) Repeated stress impairs endocannabinoid signaling in the paraventricular nucleus of the hypothalamus. J Neurosci 30:11188-11196. CrossRef Medline

Young EA, Spencer RL, McEwen BS (1990) Changes at multiple levels of the hypothalamo-pituitary adrenal axis following repeated electrically induced seizures. Psychoneuroendocrinology 15:165-172. CrossRef Medline

Zhu PJ, Lovinger DM (2007) Persistent synaptic activity produces longlasting enhancement of endocannabinoid modulation and alters longterm synaptic plasticity. J Neurophysiol 97:4386-4389. CrossRef Medline 